\title{
Post all press releases online, and give them named authors
}

\section{Ben M Goldacre research fellow in epidemiology}

London School of Hygiene and Tropical Medicine, London WC1E 7HT, UK

McCartney argues that press releases from academic journals can be misleading and suggests that guidelines, similar to CONSORT, would improve standards. ${ }^{1}$ This is a laudable aim, but with so much variation in the type and content of research articles it would be extremely complex to design, implement, and police.

In the meantime, two easily implemented changes would ensure accountability and transparency, and help improve standards. Firstly, all press releases in all academic journals should be made publicly available online, alongside the academic journal article they relate to, so that everyone can see whether the press release contained misrepresentations or exaggerations. Secondly, all academic journal press releases should give named authors, including at least one author from the academic paper itself, who take full responsibility for the contents.
In many cases - especially for research relevant to patients' choices or policy matters-the bulk of an academic paper's research impact comes from press coverage. This means that the press release is often as important as the paper itself. Press releases should therefore be accessible and treated as seriously as the academic papers themselves.

Competing interests: I receive income from writing and speaking about problems in science and science reporting.

1 McCartney M. Research press releases need better policing. BMJ 2014;348:g2868. (28 April.)

Cite this as: BMJ 2014;348:g3448

๑ BMJ Publishing Group Ltd 2014 